\section{Challenges of the Management of Stroke in Sub Saharan Africa: Evaluating Awareness, Access and Action}

\section{Bertha Chioma Ekeh}

Department of Internal Medicine, University of Uyo Teaching Hospital, Nigeria

*Corresponding author: Bertha Chioma Ekeh, Lecturer/Consultant, Department of Internal Medicine, University of Uyo Teaching Hospital, Nigeria, Tel: 234 8034018391; +234 7052088085; E-mail: berthacekeh@yahoo.com; berthaekeh@uniuyo.edu.ng

Received date: October 24, 2017; Accepted date: November 20, 2017; Published date: November 27, 2017

Copyright: (C) 2017 Ekeh BC. This is an open-access article distributed under the terms of the Creative Commons Attribution License, which permits unrestricted use, distribution, and reproduction in any medium, provided the original author and source are credited.

\begin{abstract}
Background: Stroke is one of the major public health problems in the world today. It is the third leading cause of death worldwide after ischaemic heart disease and cancer. Stroke mortality is especially high in sub Saharan Africa (SSA) which accounts for as much as $87 \%$ of all the stroke deaths. Stroke however has become a treatable disease.

Methods: We reviewed the literature on Stroke in SSA. We searched the PubMed database for studies on stroke in SSA, and included those that were community based, conducted in any SSA country and reported on awareness, mortality, risk factors and care.
\end{abstract}

Results: We found few community-based studies. Most of the studies were hospital based. There were more studies on stroke mortality and risk factors in SSA. Few studies dealt with issues of access to stroke care. Most of the studies on stroke care showed that care is still mostly supportive. South Africa however had more stroke units and state of the art stroke care than other countries in SSA.

Conclusion: There have not been many studies on optimal stroke care in SSA. The few studies seen showed that care has been majorly supportive.

Keywords: Stroke; Challenges; Management; sub-Saharan Africa; Awareness; Access; Action

\section{Introduction}

There is a large burden and mortality of stroke all over the world [1] especially so in sub Saharan Africa (SSA) which currently has the added burden of non-communicable diseases superimposed on the usual large mortality from communicable diseases. Stroke was considered an untreatable disease for many years; but is now a treatable condition. The significant advance was made when the National Institute of Neurological Disorders and stroke (NINDS) recombinant tissue plasminogen activator (rt-PA) stroke study group first reported that the early administration of rt-PA benefited some carefully selected patients with acute ischaemic stroke [2]. This breakthrough study caused a major revolution in the management of acute ischaemic stroke such that with early detection and management, there are few if any permanent sequelae [3]. Stroke care was therefore revised and adopted by many centres in the developed world.

In the current guidelines, the first goal is to prevent or reverse brain injury [4]. These include: attention to the patient's airway, breathing, and circulation (ABCs) and urgent performance of an emergency noncontrast head CT scan to differentiate between ischemic stroke and hemorrhagic stroke. Thereafter, treatments designed to reverse or lessen the amount of tissue infarction and improve clinical outcome are instituted. This falls within six categories: (1) medical support, (2) IV thrombolysis, (3) endovascular revascularization, (4) antithrombotic treatment, (5) neuroprotection, and (6) care in stroke centers and rehabilitation [4].
More than twenty years later, it is noted that many stroke patients are not getting the stroke treatment they need [5]. In view of this, the theme for 2016 world stroke day was 'FACE THE FACT: Stroke is treatable. There is an added tagline of 'Lives can improve with better awareness, access and action [5]. The right care makes a difference, but many people are NOT getting the stroke treatment they need. This paper will examine the challenges involved in optimal care found in the tagline 'Lives can improve with better Awareness, Access and Action 'in sub Saharan Africa.

\section{Epidemiology of Stroke in Africa}

Similar to coronary heart disease, stroke was thought to be rare in the African Negro until in 1977 when it was shown that stroke accounted for $0.9-4.0 \%$ of total hospital admissions and $2.8-4.5 \%$ of total deaths in Africans [6]. Other studies thereafter have recognized stroke as one of the most common neurological diseases in the black African [7-9]. In several studies from the West African sub-region, it emerged as the leading cause of adult neurological admissions, constituting up to $65 \%$ of such admissions [10-12]. Furthermore, a steady increase in stroke admissions has been observed in some institutions that have monitored their stroke admissions over time. In Tanzania, stroke admissions increased from 23 per 100000 in 1935 to 86 per 100000 in 1962 [13]. In Ghana, the number of stroke patients admitted per year increased from about 50 in 1960 to 622 in 1993, and the percentage of total adult medical admissions due to stroke increased from less than 2\% in 1960 to about 12\% in 1993 [13]. Stroke admissions to hospital therefore are clearly rising in Africa $[12,14]$. 
Average stroke incidence in Nigerian has been estimated to be $116 / 100,000$ per year [15]. Anecdotal reports estimate that every Nigerian knows or is related to somebody who has had a stroke before [16]. Studies from other African countries estimated stroke crude incidence rates ranging from 31/100 000 per year in Harare, Zimbabwe in 1998 [17] to 149/100 000 per year in Maputo, Mozambique in 2006 [18-20]. Crude prevalence rate of stroke in urban Nigeria is $1.14 / 1000$ (males 1.51, females 0.69) [21]. Nigeria is the most populous black nation hence, with this average, crude prevalence of $1.14 / 1000$, in a population of 170 million, it means that 193,800 Nigerians will suffer stroke yearly.

Stroke is the third leading cause of death worldwide after ischaemic heart disease and cancer [22] and regrettably, most of these deaths occur in the low income regions of the world [14,23] accounting for as much as $87 \%$ of all the stroke deaths [12]. This high death toll is even much more in SSA where mortality and case fatality rates are alarming ranging from $21 \%$ to as much as $50.6 \%$ [24-34]. In addition, stroke has also been noted to be a major cause of unregistered deaths in many developing countries $[14,16]$. The inference is that the above high figures therefore may actually be the tip of the iceberg since all the studies are hospital based.

\section{Face the Fact: Stroke is Treatable Awareness, Access, Action}

\section{Stroke awareness in SSA}

Stroke is generally regarded as a spiritual disease in Africa. This is majorly reflected in some of the African languages as follows: mba agbara (a hug from the spirit) in Ibo, ekpo mia (a slap from the ghost) in Ibibio and Efik, ofa (an evil arrow) in Yoruba and shan inna (paralysis by the spirit) in Hausa language. This belief spreads through other countries as shown in some of the studies. In a study carried out in Accra, 25\% of the participants believed that stroke is a spiritual illness caused by evil spirits [35] same with $13.8 \%$ of the respondents in a Nigerian study [36]. These socio-cultural beliefs affect the healthseeking behaviour; hence, many of the stroke patients are taking to traditional healers or the church for healing. One author observed that weakness of the limbs or face, especially if of sudden onset, is commonly attributed to supernatural causes by indigenes, hence the resort to herbalists for treatment in some instances [37]. In fact anecdotal reports note that one common cure amongst the Hausas in northern Nigerians is to tie a ram to the paralysed side of the body as a cure. Some relatives of patients, or patients themselves while in the hospital, would initiate discharge against medical advice to go to herbalist homes for continuation of treatment [37] being 19\% of the patients in one case [31]. Consequently, as much as $13 \%-14 \%$ of the respondents showed a preference for spiritual healing as against hospital treatment in some studies $[35,36]$. The role of traditional healing practices and practitioners in health care delivery in SSA therefore cannot be ignored and interestingly, this role is increasingly being recognized. For example, in Ghana, traditional healers have been incorporated as providers into their National Healthcare Delivery System [38]. Traditional and faith healers are often sought after to care for diabetes [39], hypertension [40] or adverse CVD outcomes such as stroke [41].

Regarding those who are aware that stroke is a medical disease, there is the issue of poor knowledge. In the study from Ghana, the organ of the body associated with stroke was noted to be the brain by $40 \%$, the heart by $10 \%$ while other aspects of the body were mentioned by $44 \%$ [35]. This is similar to a study in Uganda where as much as $76 \%$ did not recognize stroke as a disease of the brain [42]. The heart was incorrectly identified by $54 \%$ of the respondents as the injured organ during stroke [43] in Nigeria $29 \%$ did not recognize the brain as the organ affected [36]. There is also poor knowledge of the risk factors of stroke. In one study, surprisingly, lack of exercise was identified as the commonest factor (37\%) while Diabetes was least cited as a stroke risk factor (13\%) [35]. In addition, only $23 \%$ correctly listed one established stroke risk factor, $21 \%$ correctly listed two established risk factors, $14 \%$ correctly listed three established risk factors and $10 \%$ correctly listed four or more established risk factors for stroke [35]. In Uganda, the leading, risk factors identified by the participants were stress (36.6\%) and hypertension (28.9\%), respectively. None of the study participants identified cigarette smoking as a stroke risk factor [42]. The most common stroke risk factors listed by the respondents in one Nigerian study were hypertension (78.2\%) stress (59.9\%) and old age (58.3\%) [43] while only $39.8 \%$ in another study were able to mention at least 1 well-documented modifiable or potentially modifiable risk factor; hypertension though still the most recognized was by a mere $34.7 \%$ of the respondents. Other risk factors mentioned by the respondents were: diabetes (7.3\%), alcohol intake (4.5\%), smoking (3.8\%), overweight and obesity (1.9\%) and heart disease $(0.6 \%)$ [44]. Two other Nigerian studies showed a better knowledge of the risk factors where hypertension was identified as the commonest risk factor by $69.4 \%$ [45] and $88.6 \%$ [36] in the other. The study population of these two studies is worthy of note; the first was carried out in a secondary school while the second study was carried out amongst health workers. This highlights the enormous importance of education and enlightenment. In fact, it has been shown that provision of an information booklet on stroke significantly increased the knowledge of risk factors and warning signs in a sample of hospitalised stroke patients and their carers [46].

Concerning the stroke warning signs, numbness on one side was surprisingly identified as the commonest warning (44\%) while unspecified pain was the least cited (11\%) in one of the studies [35]. However, weakness (51.9\%) was the most commonly identified warning sign in a Nigerian study [45]. Expectedly, the Nigerian study carried out amongst hospital workers showed better knowledge once again in that one-sided body weakness (61.9\%) was most commonly identified as warning symptom [36]. On Further examination, over $70 \%(\mathrm{n}>485)$ of the respondents in the study from Ghana either believed that lifestyle alterations can be made to reduce the risk of stroke, or stroke is a preventable disease, or stroke requires emergency treatment [35]. Majority $(83.0 \%)$ of the respondents in one the Nigerian studies indicated that stroke was preventable whereas only $37.1 \%$ of them were aware of stroke recurrence [43]. In all, the general awareness of stroke is poor.

\section{Access to quality stroke care in SSA}

Access to optimal healthcare is a major concern in SSA. The first noted problem is the poor healthcare seeking behaviour seen over the years. One author estimated that as much as $80 \%$ of the population of a developing country like Nigeria live in rural areas and lack access to western type hospitals but rather seek care from traditional healers, churches and others [8]. This is particularly so in stroke which is commonly regarded as a spiritual disease hence the preference for spiritual healing [35-37].

Secondly, SSA is resource poor area since most of the countries are low and middle income earning countries. Unfortunately, healthcare 
has not been a priority in the budget. Therefore availability and access to health care delivery for those who opt for western type hospitals is deficient especially in the rural areas since most hospitals are located in the urban areas. Superimposed on this unavailability is the lack of infrastructure and equipment in these few hospitals. In view of this, in April 2001, the African Union countries met and pledged to set a target of allocating at least $15 \%$ of their annual budget to improve the health sector and urged donor countries to scale up support [47]. This declaration referred to as the 'Abuja Target' while being met and even surpassed by some countries like Rwanda, Liberia, Malawi, Zambia, Togo and Madagascar, is yet to be met by some others. In fact countries like Mozambique and Chad have actually slashed down their annual health spending from the budget [47]. Currently, Nigeria (most populous black nation) is way below the target. A sum of 6 trn was the Nigerian total budget in 2016. The amount allocated to healthcare was 250 bn which represents a total allocation of $4 \%$ of the total budget [48]. Due to this disparaging poor funding of health care in most countries in SSA, access to quality care remains a mirage. Hence, access to quality optimal stroke care all over SSA therefore is regrettably not in the near future. In addition to the foregoing is the cost of stroke care. In a systematic review of the cost of stroke in low and middle income countries, the highest mean direct medical cost of stroke was $\$ 8424$ in Nigeria. The lowest mean cost of stroke was in Senegal (\$416) [49]. The total cost averaged EUR 679.6 +/- 297.90 in Lome, almost 19 times higher than the minimum monthly salary of civil servants in Togo (EUR 36.30). The authors noted that the average person in Togo spends EUR 3.99 per person per year on health, while a stroke patient hospitalized in Lome spends an average of 170 times more in only 17.4 days. Accordingly, most of the Togolese cannot access specialized neurology care for a stroke [50]. Notably, there is absence of health insurance in most countries in SSA. Healthcare is majorly paid from out of pocket expenses. This outrageous cost of stroke is therefore borne by the patient and the family. Stroke therefore becomes an ostentatious disease.

The primary goal of managing a patient with acute stroke is to minimize the amount of brain damage. Central to this objective is the element of time. There are few other organs where this concept of time is critical. In SSA, persons with stroke do not present early to the healthcare facility [34,51-53]. In Senegal, most of the patients were referred to a medical centre late. Admission was before the 6th $\mathrm{h}$ for only one patient and none of the patients was admitted before the $3^{\text {rd }}$ h. Interestingly, $70 \%$ of these patients resided in the nation's capital, Dakar. Late treatment was related to the remoteness of medical centers. Among patients residing in Dakar, the first visit occurred between 6 and $24 \mathrm{~h}$ in $30 \%$ as against $7.8 \%$ in those patients residing in rural areas of the country. Educational level and socio-economic status had no effect on late treatment. The authors concluded that stroke victims receive care too late. This situation arises because of insufficiency of human and material resources and inaccessibility to care centers [34]. A similar study in Nigeria assessed the time of presentation of patients of 128 stroke patients. Only $13(10.2 \%)$ arrived the hospital within $3 \mathrm{~h}$ of the stroke. The median time of arrival was more than $3 \mathrm{~h}$ but less than one day achieved by $52(40.6 \%)$ patients. Another 41 (32.0\%) arrived after the first day but within a week. The rest of the 22 patients (17.2\%) arrived after more than a week. Similarly, the authors also found that educational status had no impact on the time of presentation. The conclusion of the study was that most of the patients presented late after the stroke. They lamented that this late presentation which is a common practice in the developing countries interfered with the acute management contributing immensely to the high mortality of stroke [51]. In Burkina Faso, the time between the onset of clinical signs and the first contact with a peripheral public health unit extended from $30 \mathrm{~min}$ to $24 \mathrm{~h}$ with an average of $6 \mathrm{~h}$ and 56 min [52] while $8.5 \%$ and $17 \%$ of the patients presented before 3 and 6 $h$, respectively at the emergency unit in another Nigeria centre [53]. This late presentation can be explained partly by poor knowledge as discussed above. However distance to the hospital and cost and mode of transportation remain a major hindrance in access to the hospital. There are few/no ambulance services in most hospital in SSA. All persons coming to the hospital make their own transport arrangements. This varies from personal cars, cabs, buses, tricycles or motor bikes. The predominant means of transport being commercial vehicles (taxi/cab) in Ghana. Local ambulance services were mostly used when patients were referred from another hospital [54]. Even in more advanced Morocco, this lack of ambulance services accounted for the delay of $120 \mathrm{~min}$ as against the SITS delay of $65 \mathrm{~min}$ [55]. Furthermore, pre-hospital care for stroke patients is unknown [34] as seen in Senegal.

Another hindrance to optimal stroke care is the unavailability of qualified personnel .There are not many neurologists in SSA to drive effective and optimal stroke care. A multi-site, hospital-based survey was conducted in 11 major referral hospitals from Ghana found acute stroke care by specialists, especially neurologists, in $36.4 \%$ [4] of the study hospitals [54]. Remarkably WHO recommendations is to reach at least the ratio of one neurologist for 50,000 people in a state, the fact in SSA is, in the "best" case, it is one for 500,000 (Ivory Coast and Senegal) [56]. In Ethiopia, the ratio was one for 10 million people 10 years ago; it is now one for 5 million. All the French-speaking countries have now at least one neurologist. Few countries have just one neurologist. There are still few (Cape Verde Islands, Gambia, Equatorial Guinea, Guinea-Bissau, Liberia, Sao Tome and Principe) who do not have a single neurologist [56]. The author of this paper has been the only neurologist in Akwa Ibom State Nigeria; a state with a population of approximately 4 million persons (as at 2006 census) [57] for the past 8 years. There were 19 responding countries in a study carried out to provide a comprehensive understanding of neurology training; 10 had no formal neurology training programs. Burkina Faso, Cameroon, Republic of the Congo, and Mozambique had an adult neurology program while only Ethiopia, Madagascar, Nigeria, Senegal, and South Africa had adult and pediatric neurology programs [58]. Among 17 of the reporting countries, there is an estimated average of 0.6 neurologists per million people. The authors concluded that 'Neurology training programs in sub-Saharan Africa are relatively limited in number and have several unmet needs including a small cadre of faculty and an opportunity to standardize curricula and financing of program's [58]. Finally, the lack of stroke units all over SSA cannot be over emphasized. Few countries in Africa as a whole have stroke units; most have only one [54,55,59].

\section{Action taken in the care of stroke in Sub Saharan Africa}

Stroke as noted earlier has become a treatable disease. On making a clinical diagnosis of stroke, there is an orderly process of evaluation and management. The first goal is to prevent or reverse brain injury [4] as noted above. Thereafter there is an urgent performance of an emergency noncontrast head CT scan to differentiate between ischemic stroke and hemorrhagic stroke. Subsequently, treatments designed to reverse or lessen the amount of tissue infarction and improve clinical outcome are instituted. The big question is 'Are these obtainable in the sub Saharan Africa? How many centres have CT scan machines? Is thrombolytic therapy available in these centres? Are there 
dedicated stroke units? One author has opined that there is limited capacity for Sub Saharan Africa hospitals to provide optimal stroke care [60]. Indeed optimal stroke care in SSA is a Herculean task.

In low-resource settings, CT scanners are either unavailable or unaffordable, forcing clinicians to make difficult clinical decision [61]. In fact, until recently many tertiary/referral hospitals in sub Saharan Africa did not have CT scan machines [24,37]. Few stroke persons were opportune to have a CT scan viz: $5.83 \% 24,11.11 \%$ [62] in Nigeria, 10\% from Madagascar [63] and even 0\% from Gambia [64]. More recently, the percentages are increasing gradually as one Nigerian study showed that $40.8 \%$ patients had CT brain, while $5.6 \%$ had magnetic resonance imaging (MRI) [65] and 34.9\% in Zimbabwe [60]. Yet another Nigerian study on stroke in the young, all the $69(100 \%)$ patients had a brain CT scan [66]. The authors however did not indicate how long it took to perform the scans. In the multisite study in Ghana [8] study sites reported having a brain computed tomographic (CT) scan, only [7] (63.6\%) were functional at the time of the study. Magnetic resonance imaging (MRI scan) services were also limited to only 4 (36.4\%) hospitals (only functional in 3) [54].

In one centre, patients were referred to the nearest hospital about $130 \mathrm{~km}$ away where the facility was available [37]. Only $31 \%$ in a Nigerian centre presented for imaging within $12 \mathrm{~h}$, while $46 \%$ failed to present within $24 \mathrm{~h}$ of symptom onset [67]. The mean presentation time for CT imaging was $70 \mathrm{~h}(\mathrm{SD} \pm 94 \mathrm{~h})$ with a median time of $24 \mathrm{~h}$. No patient presented in the time frame of less than $3 \mathrm{~h}$. Only $6(7.2 \%)$ patients presented for $\mathrm{CT}$ within six $\mathrm{h}$ of their onset of symptoms and $57(68.7 \%)$ patients presented more than $12 \mathrm{~h}$ after the onset of symptom [67]. In Burkina Faso, after arrival in medical emergencies, patients spent on average $21 \mathrm{~h}$ and $18 \mathrm{~min}$ to undergo CT scan [68].

Stroke units are a rare luxury in SSA being only one in Ghana [54] with no provision of thrombolysis using tissue plasminogen activator for acute ischemic stroke care. Thrombolysis is not available and had never been prescribed in Burkina Faso [68]. However, a first thrombolysis has actually been reported in Congo [69]. In Nigeria to the best of the author's knowledge thrombolysis has not been commenced in most centres. In most countries in SSA therefore, treatment of stroke is essentially supportive with the use of aspirin for acute ischemic stroke was reported in all the hospitals. Surgical procedures for acute stroke care such as revascularization, decompressive craniotomy, arteriovenous malformation treatment, surgery for aneurysm treatment are also rudimentary.

South Africa is the most technologically advanced country in Africa. It is the only country in sub Saharan Africa with wellestablished stroke units. Antithrombolytic drugs are administered routinely in these stroke units hence; they have similar outcomes to the developed world [70]. These centres have gone further to institute multidisciplinary stroke care noting a reduction of inpatient mortality from $33 \%$ to $16 \%$ in one case [71]. The authors however decried the fact that the number of CT brain scans performed and referral to a tertiary hospital did not increase significantly [71]. One suggestion is that a greater endeavour should be made in resource-limited settings to expand facilities to enable intravenous r-tPA treatment within the $4.5 \mathrm{~h}$ period following onset of stroke. The resources required are small with the main costs being a CT scan of the brain and the cost of r-tPA [72].

There is yet the unmet need of stroke rehabilitation facilities across SSA. Two-thirds of all families received no stroke education before discharge in a rural African setting [73]. All patients were discharged into family care as there was no stroke rehabilitation facility available to the community. Most survivors improved functionally but were left with significant disability. The authors recommended introduction of measures to improve family education and the level of home-based care in order to reduce carer strain and the degree of functional disability [73].

\section{Recommendations}

Population-based health education programs and appropriate public health policy must be developed [73]. This will largely improve the poor awareness. The emphasis should be on preventing the development of risk factors in the first place. Regrettably, some are unaware of the presence of these risk factors or are poorly controlled if know [74]. High blood pressure is the most powerful predictor of stroke, and its treatment can reduce the risk of stroke by $\geq 40 \%$ [62]. In one case however, as much as $64 \%$ of the stroke patients had the hypertension diagnosed for the first time [29]. Control of risk factors will guarantee SSA a "stroke-free" future [75]. The involvement of community and faith-based organisations in spiritually inclined SSA has a lot of merit [76]. These organisations can go a long way in health education and public enlightenment campaigns. The author of this paper has been involved in such public enlightenment campaigns in the church with amazing results.

There should be better health funding by the government as declared in the 'Abuja target. Better funding will translate to more hospital, better infrastructure, more training of neurologists and other health personnel. The net effect will be optimal stroke care. Countries in SSA should embrace health insurance either provided by the government, community or faith based organisations.

Collaboration from international organisations especially in the area of research and acute care will be of immense benefit e.g. the international health partnership to share knowledge of stroke management and service development to support the improvement of stroke care in Ghana [77].

\section{Conclusion}

There is an enormous stroke burden and mortality in SSA. Despite the fact that stroke is treatable, quality care remains a mirage in SSA. In essence, most persons in SSA are not getting the stroke care they need: Awareness, Access and Action are still very much below par. More effort is needed in all three areas.

\section{References}

1. American Heart Association (1998) Heart and stroke update, Dallas, USA.

2. The national institute of neurologic disorders and stroke rt-PA stroke study group (1995) Tissue plasminogen activator for acute ischaemic stroke. New Eng J Med 333: 1581-1587.

3. Ogun SA (2002) Management of stroke: Recent advances. Niger Clin Pract 2: 130-138.

4. Smith WS, English JD, Johnston SC (2015) Cerebrovascular disease. In Kasper DL, Fauci AS, Hauser SL, Longo DL, Jameson JL, Loscalzo J: Harrison's Principles of Internal Medicine, New York, USA.

5. Webster J, Crickmore C, Charlton K, Steyn K, Wentzel-Viljoen E, et al. (2016) South Africa's salt reduction strategy: Are we on track, and what lies ahead? S Afr Med J 107: 20-21.

6. Osuntokun BO (1977) Stroke in the Africans. Afr J Med Med Sci 6: 39-53. 
7. Spillane JD (1973) Tropical neurology. London oxford university press: 133-272.

8. Ogunniyi A, Osuntokun BO (1993) Epidemiology of neurologic illnesses in Africa. Tropical neurology symposium at the joint meeting of the World Federation of Neurology with the Royal Society of Tropical Medicine and Hygiene, London. Wemilore Press Nig Ltd., Ibadan.

9. Osuntokun BO, Bademosi O, Akinkugbe O O, Oyediran A B, Carlisle R, et al. (2010) Profile of neurological admissions at the University of Nigeria Teaching Hospital Enugu. Niger J Med 19: 4190-422.

10. Ansa V, Njideoffor U, Nworah C, Odigwe C, Otu A, et al. (2016) Patient outcomes following after-h and weekend admissions for cardiovascular disease in a tertiary hospital in Calabar, Nigeria. Cardiovasc J Afr 5: 328-332.

11. Sagui E (2007) Stroke in sub-Saharan Africa. Med Trop (Mars) 67: 596-600.

12. Connor MD, Thorogood M, Modi G, Warlow CP (2007) The burden of stroke in Sub-Saharan Africa. Am J Prev Med 33: 172-173.

13. Report of WHO (2001) Wellcome trust meeting of experts: Secondary prevention of non-communicable diseases in low and middle income countries through community based and health service intentions. Geneva: World health organisation.

14. Odusote K (1996) Management of stroke. Nig Med Pract 32: 36-62.

15. Ogungbo BI, Gregson B, Mendelow AD, Walker R (2003) Cerebrovascular diseases in Nigeria: What do we know and what do we need to know? Trop Doct 33: 25-30.

16. Matenga J (1997) Stroke incidence rates among black residents of HarareA prospective community-based study. S Afr Med J 87: 606-609.

17. Adeloye D (2014) An estimate of the incidence and prevalence of stroke in Africa: A systematic review and meta-analysis. PLoS One 9: e100724.

18. Adeloye D, Basquill C (2014) Estimating the prevalence and awareness rates of hypertension in Africa: A systematic analysis. PLoS One 9: e104300.

19. Damasceno A, Gomes J, Azevedo A, Carrilho C, Lobo V, et al. (2010) An epidemiological study of stroke hospitalizations in Maputo, Mozambique: A high burden of disease in a resource-poor country. Stroke 41: 2463-2469.

20. Danesi M, Okubadejo N, Ojini F (2007) Prevalence of stroke in an urban, mixed-income community in Lagos, Nigeria. Neuroepidemiology 28: 216-223.

21. Feigin VL, Lawes CMM, Bennett DA, Barker-Collo SL, Pang V (2009) Worldwide stroke incidence and early case fatality reported in 56 population based studies: A systematic review. Lancet Neurol 8: 355-369.

22. Bonita R (2001) Stroke prevention: A global perspective: Norris JW, Hachinski VC, editors stroke prevention, New York: Oxford University Press, pp: 259-274.

23. Ekeh B, Ogunniyi A, Isamade E, Ekrikpo U (2015) Stroke mortality and its predictors in a Nigerian teaching hospital. Afr Health Sci 15: 74-81.

24. Nyame PK, Bonsu-Bruce N, Amoah AG, Adjei S, Nyarko E, et al. (1994) Current trends in the incidence of cerebrovascular accidents in Accra. West Afr J Med 13: 183-186.

25. Joubert J (1991) The MEDUNSA stroke data bank. An analysis of 304 patients seen between 1986 and 1987. S Afr Med J 80: 567-570.

26. Sagui E, M'Baye PS, Dubecq C, Ba Fall K, Niang A, et al. (2005) Ischemic and hemorrhagic strokes in Dakar, Senegal: A hospital-based study. Stroke 36: 1844-1847.

27. Garbunsinski JN, Marianne AB, Van der sande MA, Bartholomew EJ, Dramaix MD, et al. (2005) Stroke presentation and outcome in developing countries: A prospective study in Gambia. Stroke 36: 1388

28. Bwala SA (1989) Stroke in a subsaharan Nigerian hospital-A retrospective study. Trop Doct 19: 11-14.

29. Ogun SA, Ojini FI, Ogungbo B, Kolapo KO, Danesi MA (2005) Stroke in south west Nigeria: A 10 year review. Stroke 36: 1120-1122.

30. Njoku CH, Adeloju AB (2004) Stroke in Sokoto, Nigeria: A five year retrospective study. Ann of Afr Med 2004: 73-76.
31. Komolafe MA, Ogunlade O, Komolafe EO (2007) Stroke mortality in a teaching hospital in South Western Nigeria. Trop Doct 37: 186-188.

32. Ogun SA (2003) Acute stroke mortality at LUTH. Nig J Clin Pract. 5: 38-41.

33. Sene-Diouf F, Basse AM, Ndiaye M, Toure K, Diop MS, et al. (2007) The management of cerebrovascular events in Senegal. Rev Neurol (Paris) 163: 823-827.

34. Donkor ES, Owolabi MO, Bampoh P, Aspelund T, Gudnason V (2014) Community awareness of stroke in Accra, Ghana. BMC Public Health 14: 196.

35. Akinyemi RO, Ogah OS, Ogundipe RF, Oyesola OA, Oyadoke AA, et al. (2009) Knowledge and perception of stroke amongst hospital workers in an African community. Eur J Neurol 16: 998-1003.

36. Okokhere PO, Bankole IA, Erohubie CA (2013) Characteristics, risk factors and case fatality rate of stroke in hospitalized patients in semiurban South-South Nigeria. SAGE Open Med 1: 2050312113516112.

37. Pinkoane MG, Greeff M, Williams MJ (2005) The patient relationship and therapeutic techniques of the South Sotho traditional healer. Curationis 28: 20-30.

38. Abo KA, Fred-Jaiyesimi AA, Jaiyesimi AE (2008) Ethnobotanical studies of medicinal plants used in the management of diabetes mellitus in South Western Nigeria. J Ethnopharmacol 115: 67-71.

39. Risenga PR, Botha A, Tjallinks JE (2007) Shangaan patients and traditional healers management strategies of hypertension in Limpopo Province. Curationis 30: 77-84.

40. Hundt GL, Stuttaford M, Ngoma B; SASPI Team (2004) The social diagnostics of stroke-like symptoms: Healers, doctors and prophets in Agincourt, Limpopo Province, South Africa. J Biosoc Sci 36: 433-443.

41. Kaddumukasa M, Kayima J, Kaddumukasa M N, Ddumba E, Mugenyi L, et al. (2015) Knowledge, attitudes and perceptions of stroke: A crosssectional survey in rural and urban Uganda. BMC Res Notes 8: 819 .

42. Ayanniyi O, Akande O, Mustapha AF (2006) Knowledge and perception of stroke among adults in Osogbo, Nigeria. Afr J Med Med Sci 35: $447-452$.

43. Wahab KW, Kayode OO, Musa OI (2015) Knowledge of stroke risk factors among Nigerians at high risk. J Stroke Cerebrovasc Dis 24: 125-129.

44. Komolafe MA, Obembe AO, Olaogun MO, Adebiyi AM, Ugalahi T, et al. (2015) Awareness of stroke risk factors and warning signs in Nigerian adolescents compared with adults. J Stroke Cerebrovasc Dis 24: 687-693.

45. Collins DR, McCormack PM, O'Neill D (2002) General perception of stroke. Poor knowledge of stroke can be improved by simple measures. BMJ 325: 392.

46. Ocampo AR (2013) Health funding in Africa: How close is the AU to meeting Abuja targets? Devex.

47. Emejuiwe victor (2016) Funding health care in economic recession: The guardian newspapers.

48. Kaur P, Kwatra G, Kaur R, Pandian JD (2014) Cost of stroke in low and middle income countries: A systematic review. Int J Stroke 9: 678-682.

49. Guinhouya KM, Tall A, Kombate D, Kumako V, Apetse K, et al. (2010) [Cost of stroke in Lomé (Togo).] Sante.

50. Ekeh B, Isamade E (2014) Time of presentation of stroke patients in a tertiary hospital in Northern Nigeria, West Africa. J Med Investig Pract 9: 1-4.

51. Napon C, Dabilgou A, Kyelem J, Bonkoungou P, Kaboré J (2017) Therapeutic route of patients at the acute phase of their stroke in Burkina Faso. J Neurol Sci 372: 75-77.

52. Owolabi LF, Ibrahim A (2012) Stroke in young adults: A prospective study from northwestern Nigeria. ISRN Neurol 2012: 468706.

53. Baatiema L, Otim M, Mnatzaganian G, Aikins AD (2017) Towards best practice in acute stroke care in Ghana: A survey of hospital services. BMC Health Serv Res 17: 108.

54. Chtaou N, Rachdi L, Midaoui AE, Souirti Z, Wahlgren N, et al. (2016) Intravenous thrombolysis with rt-PA in stroke: Experience of the moroccan stroke unit. Pan Afr Med J 24: 207. 
Citation: Ekeh BC (2017) Challenges of the Management of Stroke in Sub Saharan Africa: Evaluating Awareness, Access and Action. J Pediatr Neurol Med 2: 128. doi:10.4172/2472-100X.1000128

Page 6 of 6

55. Diop AG, Gouider R (2014) Neurology in Sub-Saharan Africa: Development, opportunity, hope and challenges.

56. (2006) Nigeria 2006 Census figures.

57. Mateen FJ, Clark SJ, Borzello M, Kabore J (2016) Neurology training in sub-Saharan Africa: A survey of people in training from 19 countries. Ann Neurol 79: 871-881.

58. Abd-Allah F, Moustafa RR (2014) Burden of stroke in Egypt: current status and opportunities. Int J Stroke 9: 1105-1108.

59. Kaseke F, Stewart A, Gwanzura L, Hakim J, Chikwasha V (2017) Clinical characteristics and outcomes of patients with stroke admitted to three tertiary hospitals in Zimbabwe: A retrospective one year study. Malawi Med J 29: 177-182.

60. Johnson W, Onuma O, Owolabi M, Sachdeva S (2016) Stroke: A global response is needed. Bull World Health Organ 94: 634-634.

61. Mustapha AF, Sanya EO, Bello TO (2012) Stroke among young adults at the LAUTECH Teaching Hospital, Osogbo, Nigeria. Nig Q J Hosp Med 22: $177-180$.

62. Stenumgard PS, Joshua M, Rakotondranaivo MJ, Sletvold O, Follestad T, et al. (2017) Stroke in a resource-constrained hospital in Madagascar. BMC Res Notes 10: 307.

63. Garbusinski JM, van der Sande MA, Bartholome EJ, Dramaix M, Gaye A et al. (2005) Stroke presentation and outcome in developing countries: A prospective study in the Gambia. Stroke 36: 1388-1393.

64. Owolabi LF, Ibrahim A (2012) Stroke in young adults: A prospective study from northwestern Nigeria. ISRN Neurol 2012: 468706.

65. Oyinloye O, Nzeh D, Adesiyun O, Ibrahim M, Akande H, et al. (2015) Neuroimaging of young adults with stroke in Ilorin Nigeria. Ann Afr Med 14: $82-88$

66. Ogbole GI, Owolabi MO, Ogun O, Ogunseyinde OA, Ogunniyi A (2015) Time of presentation of stroke patients for CT imaging in a Nigerian tertiary hospital. Ann Ib Postgrad Med 13: 23-28.
67. Napon C, Dabilgou A, Kyelem J, Bonkoungou P, Kaboré J (2017) Therapeutic route of patients at the acute phase of their stroke in Burkina Faso. J Neurol Sci 372: 75-77.

68. Ossou-Nguiet PM, Otiobanda (2012) First thrombolysis in acute stroke with tenecteplase in Congo. S Afr Med J 102: 541-544.

69. Bryer A, Wasserman S (2013) Thrombolysis for acute ischemic stroke in South Africa. Int J Stroke 8 Suppl A100: 112-113.

70. de Villiers L, Kalula SZ, Burch VC (2009) Does multidisciplinary stroke care improve outcome in a secondary-level hospital in South Africa? Int J Stroke 4: 89-93.

71. Jivan K, Ranchod K, Modi G (2013) Management of ischaemic stroke in the acute setting: Review of the current status. Cardiovasc J Afr 24: 86-92.

72. Wasserman S, de Villiers L, Bryer A (2009) Community-based care of stroke patients in a rural African setting. S Afr Med J 99: 579-583.

73. Lemogoum D, Degaute JP, Bovet P (2005) Stroke prevention, treatment, and rehabilitation in sub-Saharan Africa. Am J Prev Med 29: 95-101.

74. Sarfo FS, Acheampong JW, Appiah LT, Oparebea E, Akpalu A, et al. (2014) The profile of risk factors and in-patient outcomes of stroke in Kumasi, Ghana. Ghana Med J 48: 127-134.

75. Mensah GA (2003) A heart-healthy and "stroke-free" world through policy development, systems change, and environmental supports: A 2020 vision for sub-Saharan Africa. Ethn Dis 13: S4-S12.

76. Kolapo KO, Vento S (2011) Stroke: A realistic approach to a growing problem in Sub-Saharan Africa is urgently needed. Trop Med Int Health 16: 707-710.

77. Gould A, Asare H, Akpalu A, Cullen L, Easton S, et al. (2011) Development of stroke care in Ghana. Int J Stroke 6: 150-151. 